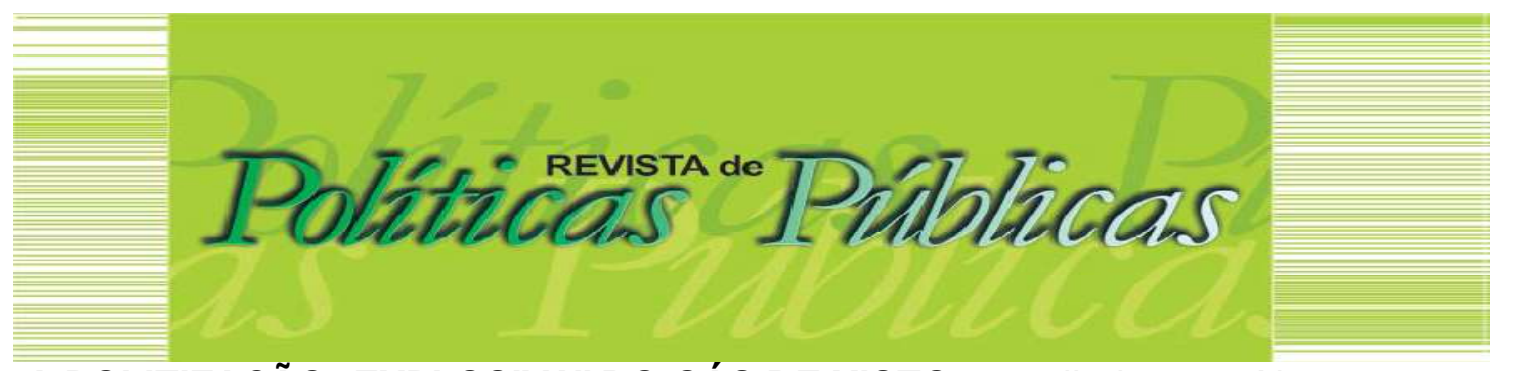

\title{
A POLITIZAÇÃO “EXPLOSIVA” DO GÁS DE XISTO: contribuições críticas para o estudo do Fracking
}

\author{
Benilson Borinelli 1 \\ Sérgio Ricardo Vitiello2
}

\section{Resumo}

O controverso método de fracking para a extração de gás de xisto e seus impactos socioambientais têm colocado em evidência as disputas acirradas em torno das decisões políticas e do estado capitalista. Diante da relevância do tema e do incipiente número de estudos no Brasil, neste artigo, analisamos como as decisões sobre o fracking vêm sendo abordadas nas perspectivas funcionalista e crítica. Desenvolvemos uma pesquisa bibliográfica e descritiva, apoiados principalmente na literatura internacional. Embora as duas perspectivas ofereçam importantes contribuições, são as críticas que melhor capturam as relações de poder em jogo nas decisões sobre o fracking e fomentam o engajamento contra novas injustiças. Mais estudos serão necessários no País dada a complexidade do tema e da vigência de projetos pró-fracking que poderão ganhar força no atual contexto de desregulamentação neoliberal.

Palavras-chave: Fracking. Gás de xisto. Decisão política. Política ambiental. Estado.

“EXPLOSIVE" POLITIZATION OF SHALE GAS DECISIONS: critical contributions to fracking study

\section{Abstract}

The controversial fracking method for shale gas extraction and its socio-environmental impacts has brought to light disputes over political decisions and capitalist state. Given the theme's relevance and the incipient number of studies in Brazil, this article analyzes how decisions about fracking have been approached from functionalist and critical perspectives. We developed a bibliographic and descriptive research, supported mainly by international literature. While both perspectives make important contributions, critiques' ones can best capture the power relations at stake in decisions about fracking and foster engagement against new injustices. Further studies will be needed in Brazil due to the theme complexity, the continuity of pro-fracking projects and the current intensification of neoliberal deregulation of environmental policies.

Keywords: Fracking. Shale gas. Political decision. Environmental policy. State.

Artigo recebido em: 11/10/2019 Aprovado em: 23/04/2020 DOI: http://dx.doi.org/10.18764/2178-2865.v24n1p68-86.

\footnotetext{
1 Administrador. Doutor em Ciências Sociais (UNICAMP). Mestre em Administração Pública (UFSC). Professor Associado do Departamento de Administração e do Programa de Pós-Graduação em Administração (PPGA) da Universidade Estadual de Londrina (UEL). Coordenador do Grupo de Pesquisa em Política e Gestão Socioambiental. Rodovia Celso Garcia Cid Pr 445 Km 380 - Londrina - Caixa Postal 10.011 - Campus Universitário, PR, 86057-970. E-mail: benilson@uel.br

2 Bacharel em Direito e Geografia. Especialista em Administração Industrial pela Universidade Estadual de Londrina (UEL). Vinculação: Discente do Programa de Pós-graduação em Administração (PPGA) da Universidade Estadual de Londrina (UEL). e-mail: sergio.vitiello@uel.br
} 


\section{INTRODUÇÃO}

Desde os anos 1990, avanços tecnológicos nos Estados Unidos possibilitaram o que antes parecia impossivel, a extração de gás de rochas de xisto, formadas há milhões de anos, por meio do fraturamento hidráulico, ou fracking, em inglês, em escala e preços atrativos para a exploração comercial. Desde então, a técnica de gás não convencional, que recorre a explosões com um composto de centenas de produtos químicos e milhões de litros de água, é apontada como uma revolução energética (MCELROY; LU, 2013) da matriz dos hidrocarbonetos, na contramão das demandas por fontes sustentáveis. Favorecida pelo contexto da neoliberalização da natureza global (CASTREE, 2008) e pela disponibilidade de reservas na grande maioria dos continentes, a técnica disseminou-se pelo mundo a partir de meados dos anos 2000. Contudo, em diversos lugares, as suas vantagens econômicas em relação a outras fontes energéticas fósseis vêm sendo confrontadas pelos potenciais riscos de profundas transformações e impactos sociais, econômicos e ambientais, alguns ainda não conhecidos completamente (OCHANDIO; D' ELIA; 2014).

Desde 0 conhecimento dos seus impactos, em diversos países, o fracking protagoniza disputas entre forças favoráveis e contrárias à atividade, mobilizando e articulando redes de empresas, governos, centros de pesquisa, organizações governamentais nacionais e internacionais, grupos e movimentos locais. Essas forças tentam influenciar decisões governamentais, em diversos níveis, para resistir, restringir ou favorecer a exploração pelo fracking, alcançando resultados variados (HOLANDA, 2017). Nessas batalhas, as ciências sociais e naturais são convocadas pelas diferentes coalizões, destacando a centralidade do conhecimento científico para fundamentar e legitimar decisões políticas sobre os riscos de um fenômeno complexo, incerto, politizado e explosivo (BECK, 2010).

Representando um novo regime de natureza, um tipo específico de tecnonatureza (VESALON; CRETAN, 2015), o fracking desafia e transforma padrões de desenvolvimento, capitalistas ou não, de políticas públicas, de riscos e conflitos socioambientais e, por conseguinte, as relações de forças que disputam as decisões do Estado capitalista na contemporaneidade. Nesse movimento, mudanças materiais e discursivas engendradas pelo fracking representam um momento crítico para pensar os limites e o potencial de resistência da sociedade, do Estado e das políticas ambientais em diferentes contextos e espaços. No Brasil, o uso de fracking para exploração de gás de xisto ganhou notoriedade em 2013, após o lançamento da $12^{2}$ rodada de licitações da Agência Nacional do Petróleo, Gás Natural e Biocombustíveis (ANP), que ofertou, sem consulta à população afetada e sem avaliação de impactos ambientais, 72 blocos de exploração do gás. Como em outros lugares, a politização do tema mobiliza um grande e variado número de atores, instâncias governamentais, controvérsias e decisões governamentais. Até 0 momento, apesar de algumas vitórias da coalizão antifracking 
(BORINELLI, HISAMATSU; VITIELLO, 2018), o futuro da exploração do gás de xisto continua em aberto no País. Por se tratar de um tema multifacetado, complexo, recente e de grande relevância social, ambiental, econômica e política, o fracking representa uma grande possibilidade e necessidade de estudos, ainda pouco desenvolvidos no Brasil. Neste artigo, pretendemos contribuir para esse debate no país, particularmente no âmbito das ciências sociais, apresentando criticamente como as decisões sobre o fracking vêm sendo abordadas nas perspectivas funcionalista e crítica.

A produção bibliográfica sobre a política do fracking cresceu significativamente na última década, no rastro da difusão e do caráter inédito e controverso do método. O nosso propósito com este artigo é contribuir para a disseminação do debate sobre o fracking, apresentando-o como um tema complexo, contestado e aberto, em seu estudo e decisões públicas, a diversas epistemologias políticas. Com isso, esperamos chamar a atenção para a relevância do tema e estimular novos estudos e discussões no contexto brasileiro. As ciências sociais, mas não só, cumprem um papel relevante em antecipar as consequências ambientais e sociais de economias políticas globais (WHITE; WILBERT, 2009) contemporâneas, como o fracking. Dessa forma, elas podem participar ativamente do movimento de correlações de forças nas disputas, geralmente assimétricas, sobre uma atividade complexa, que poderá promover novos e complexos desafios para as políticas públicas, bem como reforçar e ampliar as diversas formas de violência, externalizações e injustiças socioambientais (ZHOURI, 2018; SVAMP, 2014).

Adotando uma metodologia de pesquisa bibliográfica e exploratória, recorremos a artigos e livros, principalmente da literatura internacional, disponibilizados em bases de dados como Web of Science, Scopcus e Scielo. Após a organização e a leitura do material levantado, optamos por apresentar e discutir o fracking conforme duas perspectivas gerais e representativas das abordagens epistemológicas nas ciências sociais: a funcionalista/pluralista do Advocacy Coalizon Framework ou Modelo de Coalizões de Defesa (MCD), uma das mais adotadas internacionalmente, e aquelas que estamos denominando de críticas, a pós-estruturalista e a estruturalista com foco no Estado e no território capitalista. Esta última, na falta de um número representativo de estudos, assume um caráter mais propositivo. Para cada uma das perspectivas, buscamos apontar e descrever as principais características, categorias priorizadas e alguns resultados e limites. 0 recorte realizado, evidentemente, não contempla o grande número e variedade de estudos existentes, mas acreditamos que ele possa oferecer uma profícua e estimulante aproximação com o debate sobre o fracking.

Além desta introdução, o artigo possui mais duas partes. Na primeira, destacamos aspectos conceituais e históricos e os impactos socioambientais atribuídos à tecnonatureza do fracking. $\mathrm{Na}$ segunda parte, discutimos algumas das possíveis abordagens para o estudo do fracking, finalizando com uma breve descrição da sua recente trajetória no Brasil. 


\section{O FRACKING COMO TECNONATUREZA}

O fraturamento hidráulico compreende uma variedade de técnicas que permite a extração de combustíveis líquidos e gasosos do subsolo combinando o uso de explosões e água. Os primeiros registros do uso do fraturamento hidráulico nos Estados Unidos datam da década de 1860, mas o fracking moderno passou a ser usado a partir de 1947 para a produção alternativa e mais lucrativa de petróleo e gás natural convencional. O uso e o aperfeiçoamento do fracking para a extração de hidrocarbonetos não convencionais (gás de rochas de folhelho, popularizado como gás de xisto) resultaram da obstinação e das pesquisas iniciadas nos anos 1980, por George Mitchell, engenheiro, geólogo, multimilionário e um dos barões do gás natural mais poderosos do Texas. Ele é apontado como um dos principais responsáveis pela mais importante e a maior inovação em energia deste século e por ressuscitar a indústria de petróleo e gás dos Estados Unidos (GERTNER, 2013). Com uma das maiores reservas de gás de xisto do mundo, o método se disseminou no país a partir dos anos 1990 devido a uma conjunção de fatores: avanços tecnológicos; concessão de crédito público e legislações favoráveis; o direito de qualquer cidadão a explorar os recursos minerais do subsolo de sua propriedade e a regulação da exploração descentralizada para os estados (MERRILL, 2013).

O fracking desenvolvido por Mitchell permitiu extrair o gás natural aprisionado nas rochas de xisto, denominadas rochas mãe ou geradoras, formadas há milhões de anos. A extração de gás de forma não convencional começa da mesma forma que a exploração convencional (Figura 1), ou seja, verticalmente por tubos de aço presos às paredes do poço revestidos com cimento (D'ELIA; OCHANDIO, 2014). Essa tubulação atravessa formações de água doce continuando até chegar a um ponto de inflexão, quando passa a ser inclinada ou horizontal. Após a perfuração até o depósito de gás, em geral a partir de 1000 metros de profundidade, explosões acionadas por um canhão de pulsão colocam a tubulação em contato com as rochas. Em seguida são injetados milhões de litros de água, areia e centenas de produtos químicos sob alta pressão, incluindo nanopartículas orgânicas e inorgânicas, que fraturam a rocha em milhões de partes. Os canais abertos nas rochas pelo composto químico permitem que o gás circule e seja extraído para a superfície. 0 retorno do fluido de gás à superfície é acompanhado por boa parte dos fluidos injetados, que são armazenados em represas ou em tanques coletores (D'ELIA; OCHANDIO, 2014). 
Figura 1 - Processos de extração de gás convencional e não convencional

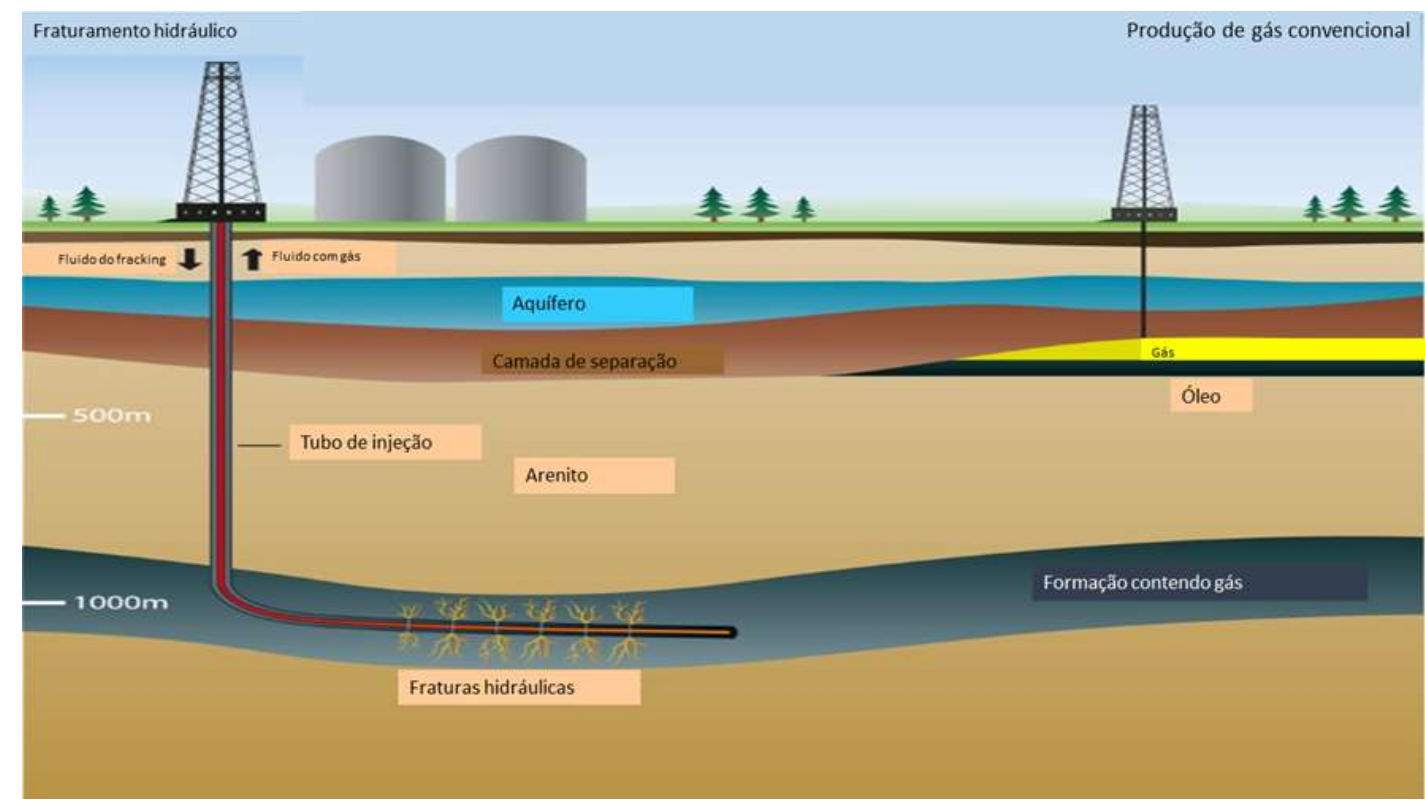

Fonte: Vertex (2019), traduzido pelos autores.

Os defensores do fracking advogam ganhos como a redução de preços e da dependência externa, geração de empregos e de tributos e benefícios ecológicos. A produção de gás não convencional vem sendo apresentada como uma "ponte", uma transição para fontes renováveis, na medida em que emite menos gases de efeito estufa do que outros combustíveis fósseis, como o carvão e o petróleo (HOWARTH, 2014). Contudo, esses prováveis benefícios são questionados devido a diversas externalidades ambientais e sociais negativas na forma de riscos e impactos que a atividade do fracking pode promover. Esses riscos ambientais estão relacionados principalmente ao fluido químico utilizado, com grande potencial tóxico para os seres vivos e o meio ambiente. A composição do fluido pode conter de 600 a 900 produtos químicos, entre eles, dicloretano, querosene e diesel, metanol, formaldeído, éter de glicol, ácido clorídrico e hidróxido de sódio, que podem contaminar a água, o solo e o ar pela evaporação (D' ELIA; OCHANDIO, 2014). Há riscos de falhas estruturais no poço, que podem causar vazamentos para aquíferos e subsolo, e diversos acidentes têm contaminado a água, o solo e as formas de vida por derramamento de materiais tóxicos armazenados em tanques e fossas e transportados por caminhões ou oleodutos (PETERSON et al., 2017; D' ELIA; OCHANDIO, 2014). Um obstáculo para conhecer e avaliar o impacto desses materiais é que a composição do fluido, muitas vezes, é sigilosa por força da proteção das patentes.

Embora emita menos CO2 que o carvão e o óleo, o gás natural é composto principalmente de metano, um gás de efeito estufa extremamente potente. Howarth (2019) constatou que o gás natural (o convencional e o de xisto) é responsável por grande parte dos recentes aumentos nas emissões de metano no planeta e que, além de contribuir sobremaneira para as mudanças climáticas, essas 
emissões elevam os níveis de ozônio no solo, com danos significativos à saúde pública e à agricultura. Alguns outros problemas associados ao fracking são explosões; abalos sísmicos; maiores riscos ocupacionais aos trabalhadores em relação a outros setores; aumento do custo de vida, do preço e da escassez de terras, da prostituição, da criminalidade e de acidentes de trânsito; elevado consumo e conflito hídrico (OCHANDIO; D’ELIA, 2014; GARDINER, 2017).

As informações apresentadas até aqui não pretendem esgotar o conhecimento disponível sobre o fracking, mas apontar aspectos gerais sobre esse fenômeno, sua complexidade e o caráter incerto, controvertido e contestado que reveste as decisões políticas em torno dele. Os resultados de decisões políticas sobre a autorização ou não da atividade do fracking, a declaração de moratórias e sob que condições o processo se dará variam de acordo com o país e unidades subnacionais. Enquanto alguns países e estados liberaram a atividade, como Argentina, Canadá, China e alguns estados dos Estados Unidos - como Texas e Colorado -, outros, a exemplo da Alemanha, Bulgária, Espanha, França, Irlanda, República Tcheca e alguns estados dos Estados Unidos - como Nova lorque -, aprovaram leis proibindo a exploração do gás de xisto (HOLANDA, 2017).

A extração do gás natural do xisto pode ser interpretada como um regime de natureza tecnonatural, que coexiste, conflita e se sobrepõe aos regimes orgânico (tradicional) e capitalista (ESCOBAR, 2005). A tecnonatureza engendra um contexto particular de recombinação inédita de elementos artificiais e naturais (ESCOBAR, 2005), caracterizados pelo controle cada vez mais aprofundando das microescalas de corpos (humanos e não humanos), por meio, por exemplo, das tecnociências moleculares e da nanotecnologia. Como tal, a disposição singular de artefatos químicos, físicos e tecnológicos do fracking exige um novo ambiente de concepções sobre relações natureza e sociedade, de decisões econômicas, políticas e marcos regulatórios (VESALON; CREATAN, 2015).

A principal força internacional para a disseminação do fracking são o governo e as grandes empresas petrolíferas norte-americanas, detentoras da maior parte das patentes e do pacote de serviços e produtos (prospecção e exploração) do método. Para assegurar o aprofundamento dos interesses econômicos, comerciais e geopolíticos dos Estados Unidos, agências desse país assessoram, técnica e politicamente, e pressionam, por meio diplomático e político, autoridades públicas de países com reservas de xisto para garantir margens de lucro e estruturas regulatórias favoráveis. Um dos tópicos dessas assessorias é a gestão do conflito social e das resistências esperadas de comunidades afetadas (OBSERVATORIO PETROLERO SUR; D’ELÍA, 2014). Assim, o fracking encontra-se entrelaçado a redes de interesses e de poder internacionais, que, nas últimas décadas, se propagam mais facilmente em um ambiente neoliberal.

Como diversos estudos apresentados neste artigo ilustram, o potencial disruptivo do fracking é objeto de sistemáticas, cumulativas e acirradas disputas e contestações materiais e 
discursivas, mobilizadas por coalizões que, na disputa pelas decisões políticas, elaboram novos sentidos, estratégias e formas de resistência segundo coordenadas temporais, espaciais e multiescalares particulares.

\section{ABORDANDO A POLÍTICA DO FRACKING}

Neste tópico, apresentamos duas perspectivas gerais, e de certa forma opostas, para a análise política das decisões sobre o fracking encontradas na literatura. Acrescentamos uma exposição sobre as contribuições de se considerar o estado capitalista e o território para essa análise.

\subsection{A abordagem pluralista do Modelo de Coalizão de Defesa}

O Modelo de Coalizão de Defesa tem sido uma recorrente forma de análise das experiências de decisões políticas controversas e acirradas sobre a permissão ou não para a exploração do fracking em diferentes países e unidades subnacionais (POLICY DEBATES..., 2016; HEIKKILA et al., 2018; OLOFSSON et al., 2018). O MCD trata de problemas complexos, com várias ramificações institucionais, econômicas e sociais, característica de uma rede de políticas públicas, envolvendo disputas entre coalizões concorrentes, técnicas importantes e múltiplos atores que tentam influenciar as decisões de autoridades governamentais em um subsistema de política pública específico. Esse modelo procura analisar o processo, os resultados e impactos da política respondendo algumas questões: Como mobilizar as pessoas para manter e agir em coalizões de defesa? Até que ponto ocorre 0 aprendizado dos aliados e dos adversários? Qual é o papel dos cientistas e da informação científica e técnica na elaboração de políticas? Que fatores influenciam importantes mudanças na política? (WEIBLE; SABATIER; MCQUEEN, 2009).

Assumindo uma perspectiva sistêmica e pluralista, o MCD procura ser uma abordagem abrangente e integradora considerando fatores internos e externos relacionados ao subsistema da política pública. Nesse sentindo, destacam-se, internamente, questões como crenças, valores, mobilização de recursos (financeiros, conhecimento técnico/informações, e membros e autoridades legais), capacidade de liderança, regras institucionais e estratégias das coalizões. Externamente, um conjunto de eventos exógenos estáveis (atributos da área do problema nas regras constitucionais, nos valores sociais) e fatores externos dinâmicos (mudanças no contexto socioeconômico e político, na opinião púbica e nas coalizões governamentais) pode afetar as restrições e oportunidades dos atores e das coalizões. Assim, todos esses pontos podem influenciar e são elementos a serem considerados na 
construção das estratégias de ação das coalizões e de seu sucesso ou fracasso na busca de seus objetivos (WEIBLE; SABATIER; MCQUEEN, 2009).

Ingold et al. (2016), em uma avaliação de trabalhos apresentados na coletânea Policy Debates on Hydraulic Fracturing: Comparing coalition politics in North America and Western Europe, oferecem uma interessante leitura das características da perspectiva do MCD e dos achados sobre as decisões em torno do fracking em diversos países. Os trabalhos da coletânea objetivam identificar as coalizões, e seus atributos, que atuam no subsistema de políticas de desenvolvimento de gás não convencional. Esse subsistema é descrito considerando a estrutura constitucional, as regras institucionais, o grau de maturidade e autonomia do subsistema e os atributos específicos do tema fracking. As coalizões que tentam influenciar o processo político - decisões, reversão de decisões e outros temas relacionados, como a divulgação de informações técnicas - são caracterizadas segundo as crenças dos atores políticos, tipo de atores e sua afiliação organizacional, padrões de coordenação entre os membros da coalizão e os diferentes tipos de recursos e estratégias mobilizados. A seguir, destacamos alguns dos principais pontos ressaltados por Ingold e seus parceiros.

As regras institucionais (a exemplo das constitucionais em relação às atribuições decisórias da exploração e dos direitos de propriedade sobre o gás), o grau de maturidade dos subsistemas de políticas e o grau de autonomia do subsistema são fatores importantes nos resultados encontrados. As características inerentes ao fracking, como a localização, a quantidade e a qualidade do gás, afetam a viabilidade técnica, econômica e os riscos e benefícios sociais, culturais e econômicos da extração. Moldam, assim, combinadamente, o potencial de mobilização e os conflitos políticos. As coalizões podem atuar em diferentes instâncias de governo - nacional, estadual e local -, beneficiando-se ou mudando regras institucionais que favoreçam as suas demandas.

A coalizão pró-fracking geralmente apoia a sua expansão e desenvolvimento, ou pelo menos se opõe a uma proibição, exaltando a crença nos benefícios do crescimento econômico (empregos, renda, impostos, bem-estar), supostamente trazidos pelo fraturamento hidráulico, além da independência energética e a liberdade de pesquisa e tecnologia. A coalizão antifracking destaca aspectos de riscos ambientais (sobretudo a contaminação da água e do solo) e de saúde, 0 comprometimento da transição para fontes de energia renováveis e a grande incerteza que paira sobre o fracking.

Embora, em geral, atores dos setores econômicos tendam a se alinhar no apoio ao fraturamento, representantes da indústria e grupos de interesse ligados aos setores da agricultura, pesca, turismo e mesmo de energia concorrentes, muitas vezes, são contrários à exploração, como ocorre em regiões da Suécia, Suiça, França e Canadá. Nesse caso, esses atores fazem alianças com partidos verdes e de esquerda, setores governamentais e movimentos ambientais para resistir ao 
fracking (INGOLD et al., 2016). Os autores constatam que há variações substanciais em como atores políticos percebem a questão do fraturamento, nos padrões de coordenação, nas estratégias que empregam e nas formas como essas variações moldam os resultados políticos. Isso desloca a maior importância na análise, em termos de oportunidades essenciais e restrições às coalizões, de fatores externos para os situados no contexto do subsistema do fracking, tais como estrutura constitucional, regras institucionais e atributos específicos da exploração do gás de xisto.

Uma das recomendações para futuras pesquisas é a necessidade de estudos e de aprimoramento metodológico para analisar os recursos e as estratégias das coalizões, área pouco desenvolvida no MCD, até então, e que deverão lidar com "conceitos centrais e tradicionais no estudo da política, isto é, poder e influência" (INGOLD et al., 2016, p. 261).

A vinculação do MCD ao pluralismo implica que ele compartilha a crença liberal no poder disperso (grupos), no governo representativo e em um Estado liberal neutro. Metodologicamente, a abordagem tende a priorizar a previsão e o controle de variáveis em estudos microssociais, revelando seu alinhamento com uma perspectiva mais conservadora do que de transformação da sociedade. 0 território das abordagens pluralistas é bastante complexo e variado e, nas últimas décadas, tem demonstrado maior abertura para analisar a igualdade de acesso e influência alcançada por grupos de interesse no mundo real da política (DRYZEK; DUNLEAVE, 2009). Algumas versões neopluralistas, como a liderada por Charles Lindblon, ao apontar a privilegiada posição dos negócios nas decisões políticas, com grande poder para constranger o que o Estado pode fazer, converge em seus resultados com análises do marxismo funcionalista (DRYZEK; DUNLEAVE, 2009). No entanto, esse não é o caso, em geral, dos estudos sobre fracking que adotam o MCD, como afirmam lgold et al. (2016).

Embora o MCD reconheça que poucos agrupamentos têm reais condições de influenciar o processo político, a opção de focar mais as ideias do que os interesses e a maior preocupação com os atores e grupos de interesse - assumidos como blocos constituintes da vida política - deixa à margem o marco histórico-institucional que condiciona e constrange as decisões, como as coordenadas estruturais capitalistas no âmbito econômico e na atuação política, incluindo a democracia e o Estado (GOLDBLATT, 1996) . Ao não captar ou dar pouca importância às várias características estruturais dos sistemas sociais (DAVIDSON; FRICKEL, 2004), o MCD, ainda que possa oferecer um rico acervo de dados sobre o processo político, não problematiza as diversas desigualdades e injustiças sociais e ambientais que constituem esse processo e dele decorrem, naturalizando, assim, as sociedades liberais capitalistas. Essa preocupação vai assumir maior centralidade nos estudos críticos. 


\subsection{Estudos críticos sobre o fracking}

Num sentido amplo, entendemos como estudos críticos aqueles orientados por diversas vertentes teóricas e metateóricas (a exemplo da teoria da complexidade, do realismo crítico, da abordagem relacional estratégica, da crítica marxista da economia política, das críticas emancipatórias e do trabalho foucaultiano sobre regimes de verdade) que se ocupam da crítica à ideologia e às várias formas de dominação e "culminam em propostas de alternativas sub ou contra-hegemônicas e ações correspondentes" (JESSOP; SUM, 2016, p. 105). Portanto, esses estudos estão comprometidos não apenas com o rigor analítico - força lógica, apelo teórico -, mas também com um apelo normativo à transformação prática do mundo pautada por princípios como a justiça, emancipação, democracia e igualdade.

Estudos críticos sobre a exploração de fracking adotam perspectivas mais identificadas com o pós-estruturalismo (DRYZEK; DUNLEAVY, 2009). Ainda que possam recorrer às coalizões para distinguir e agrupar forças favoráveis e contrárias à atividade, diferenciam-se dos anteriores pelo engajamento crítico ao priorizar em suas análises as desigualdades inerentes aos processos decisórios e de distribuição dos resultados e riscos do fracking (DAVIDSON, 2017) a partir de recortes de raça, classe, gênero e outras opressões (FINLEY-BROOK et al. 2018; MCHENRY, 2017). Além disso, fazem uso de uma abordagem abrangente e articulada para superar compreensões fragmentadas da justiça. Por exemplo, a Justiça Energética Crítica engloba reconhecimentos, justiça ambiental, distributiva e processual como conjuntos transformadores de inter-relações (FINLEY-BROOK et al. 2018).

Frequentemente, tais estudos assumem explicitamente 0 ambiente neoliberal como 0 estágio capitalista, estruturalmente arraigado nas instituições, em que as batalhas pelo fracking se desenrolam e tendem a produzir privilégios, desigualdades e injustiças (VESALON; CRETAN, 2015; HUDGINS; POOLE, 2014). Procuram investigar e desconstruir discursos e estratégias pró-fraturamento quando o Estado ("mínimo") e o capital usam a sua autoridade para fabricar o consentimento, inclusive desinformando e deslegitimando discursos adversários para extrair e acumular capital (HUDGINS; POOLE, 2014; FINEWOOD; STROUP, 2012).

Contudo, esses estudos, em geral, dão pouca atenção a uma análise mais sistemática do Estado nas sociedades capitalistas, esse objeto de diversas vertentes que se ocupam da crítica marxista à economia política e à ecologia política. A escassez de trabalhos sobre o fracking que adota essa perspectiva não deve levar a crer que ela não pode oferecer importantes contribuições para uma avaliação mais ampla e rica desse fenômeno. A seguir, apontamos um breve apanhado de algumas ideias e autores que poderiam sustentar essa perspectiva a partir, principalmente, da dimensão ambiental. 
As abordagens marxistas tentam compreender tanto a crise ambiental como as respostas estatais a ela a partir da dinâmica da economia e da sociedade capitalistas. Nesse sentido, ainda que sujeito a variadas formas ao longo do espaço e do tempo, caberia ao Estado garantir as condições de produção necessárias ao crescimento econômico perpétuo, bem como a legitimação social e ambiental das contradições resultantes desse processo. O Estado operaria como um espaço estratégico, relacional e seletivo disputado por diversas forças capitalistas nacionais e internacionais (JESSOP, 2016), inclusive, entre essas, as anticapitalistas, que procuram ocupar uma posição política privilegiada, por exemplo, nas instâncias do Executivo, do Legislativo e do Judiciário, para viabilizar os seus projetos. Os governos, portanto, representam a condensação temporária de forças que se apresentam para conduzir, sob formas ideológicas específicas, a exemplo do neoliberalismo, padrões de acumulação que combinam modos de produção, de consumo e de legitimação particulares.

$\mathrm{O}$ desempenho das instituições e políticas públicas expressaria as respostas possíveis e sempre restritas à necessidade de compatibilizar as demandas incessantes por crescimento (acumulação) e as garantias de qualidade ambiental, claramente com prioridade às primeiras. A dependência econômica/fiscal e política do Estado em relação ao crescimento econômico é o principal fator a se considerar (GOLDBLATT, 1996). A tendência estrutural de favorecer a externalização dos custos ambientais da produção e do consumo capitalistas, lançando mão da não ação, da regulamentação branda, de políticas simbólicas e da legitimação de curto prazo, tem como contraponto mais importante a pressão e a resistência de movimentos sociais e ambientais. Assim, esses movimentos podem aumentar o potencial do Estado de promover melhorias ambientais dentro das economias capitalistas (O'CONNOR, 2000).

O fracking instiga uma análise espacial/temporal mais ampla da dinâmica do estado capitalista, a qual é oferecida pela leitura da geografia crítica a partir do território como categoria central. "O território é o palco da proliferação do capital, espaço apropriado pelos agentes do capital através da divisão social do trabalho" (SAQUET; SILVA, 2008, p. 34). Aqui, o fracking seria expressão da inserção de "novos" atores/interesses, discursos e padrões de exploração do espaço, cujo poder hegemônico global os coloca em situação de provocar profundas transformações no território: uma reterritorialização pelo fracking. $O$ avanço da extração do gás de xisto movido pelo capital internacional, em aliança com o grande capital nacional e o Estado, poderia contribuir para que se intensificasse, principalmente em países periféricos, a divisão territorial do trabalho, aprofundando o desenvolvimento desigual e as consequentes violências socioambientais a populações e regiões mais vulneráveis.

A indústria do gás de xisto é o mais recente caso de neoextrativismo, ou a quarta geração do extrativismo, na América Latina (GUDYNAS, 2016). O fracking, muito provavelmente, tende a reproduzir a dinâmica degradadora da indústria mineradora, em que a (des) ordem institucional do 
estado capitalista periférico (BORINELLI, et al., 2019), favorável à ordenação temporal/espacial do gás de xisto, inclina-se a reforçar e ampliar as diversas formas de violência, externalidades e injustiças socioambientais (ZHOURI, 2018). Como constatou SVAMPA (2014) no caso do fracking na Argentina, 0 avanço da fronteira de hidrocarbonetos sobre territórios e comunidades vulneráveis decreta zonas de sacrifício, ou "a radicalização de uma situação de injustiça ambiental", pois não apenas subordinam territorialidades subalternas a outra dominante, mas impõem a degradação desses territórios e da qualidade vida, legando graves danos à saúde dessas comunidades e às suas culturas e economias tradicionais (SVAMPA, 2014, p. 149).

A expansão da fronteira do capital para o interior da matéria e da célula viva, por meio, por exemplo, da nanotecnologia (WHITE; WILBERT, 2009), ilustra, como assinalaria a tese do capitaloceno, um movimento recente da compulsão histórica e destrutiva do capitalismo por energia, natureza e trabalho baratos (PATEL; MOORE, 2016). Nessa perspectiva, o fracking seria também uma frente da expansão capitalista global que se move pela lógica da acumulação por espoliação, aquela que se vale da força, da violência, da fraude, da opressão e da pilhagem para abrir novas fronteiras de investimento/acumulação, escoadouros lucrativos, em resposta à crise de sobreacumulação recente (HARVEY, 2014). Na era da financeirização neoliberal, poderosas forças globais e suas organizações representativas vêm atuando material e discursivamente para transferir ativos públicos e coletivos (como água, florestas, solo) para empresas privadas, aprofundando o desenvolvimento desigual e concentrador do capitalismo mundial.

Ainda que na fase da neoliberalização da natureza ocorra um processo amplo de desregulamentação ambiental por meio do desmantelamento da "interferência" estatal, para implementar políticas públicas que facilitem a privatização e comercialização de esferas cada vez mais amplas da vida social e ambiental (CASTREE, 2008), o Estado continua tendo um papel vital no processo político. Como afirma Harvey (2014, p. 111), o Estado "[...] constitui a entidade política, o corpo político, mais capaz de orquestrar arranjos institucionais e manipular as forças moleculares de acumulação do capital para preservar o padrão de assimetrias nas trocas mais vantajoso para os interesses capitalistas dominantes que trabalham nesse âmbito.". Como virtual gestor do território, de suas tensões, contradições e crises, é o geopoder do estado capitalista que "torna possível para o capital tratar a superfície da terra como um depósito da natureza barata" (PARENTI, 2016, p. 182). Como um tipo específico de relação social de forças (JESSOP, 2016), o Estado pode ser, ao mesmo tempo, um espaço estratégico para as forças de contestação e de resistência a formas de acumulação por espoliação como o caso estudado. Nas disputas em torno do fracking em vários países (HOLANDA, 2017; POLICY DEBATES..., 2016) e no Brasil (BORINELLI; HISAMATSU; VITIELLO, 2018), a coalizão de interesses capitalistas dominantes do estado regional e movimentos 
socioambientais pode atuar ativamente e com relativo sucesso na produção de decisões que levem à proibição da exploração do gás de xisto.

Aqui poderia ser questionado como esse novo contexto afeta a seletividade estrutural do estado capitalista (OFFE, 1984) e fomenta alianças improváveis entre atores econômicos e movimentos ambientais, movidas por novas solidariedades diante de incertezas e riscos de grandes proporções (BECK, 2010) para os territórios. Isso também implica em admitir que a resistência ao fracking constitui-se muitas vezes em vitórias parciais de disputas, canibalizantes, entre frações de capitais, algumas representantes de outras tecnonaturezas, como o agronegócio. Essas vitórias parciais, que fortalecem e legitimam formas capitalistas tradicionais de produção de riscos e de degradação socioambiental, sugerem que o Estado é uma categoria analítica e política importante, mas não suficiente, a se considerar nas lutas pela justiça ambiental e transformação das sociedades capitalistas.

Ao chamar atenção para a importância de fatores macrossociais, os marxistas ecológicos têm recebido diversas críticas pelo determinismo na atribuição do papel do Estado e das forças sociais e econômicas na produção da degradação social, dando pouca atenção à alta variabilidade nos recursos e processos ambientais e aos meios pelos quais os dilemas ambientais são socialmente construídos. Na abordagem ecomarxista, ainda são marginais discussões sobre antropocentrismo e o etnocentrismo (CASTRO, 2004). Em parte, as abordagens pós-estruturalistas são uma resposta a essas lacunas (WHITE; WILBERT, 2009). Diferentemente da "neutralidade" e do foco nos subsistemas da política pública típicos do MCD, as abordagens marxistas permitem captar relações e dinâmicas mais amplas no tempo e no espaço, em diferentes escalas, que interferem nos processos políticos regionais e locais, combinando uma crítica político-econômica das principais tendências de acumulação de capital com o compromisso com a transformação social radical (CASTRO, 2004).

Por fim, cabe um breve comentário sobre a situação do fracking no Brasil. Segundo dados da Agência Internacional de Energia publicados na imprensa, o País possui a décima maior reserva de gás de xisto do mundo (BARBOSA, 2014). O debate sobre a exploração do gás de xisto no Brasil foi desencadeado com a realização, sem consulta pública, avaliação de impactos e regulamentação específica, da $12^{a}$ rodada de licitações da ANP em 2013, na qual foram ofertados 72 blocos de exploração. Os blocos cobriam 10 estados das regiões norte, nordeste, sudeste e sul e estão sobrepostos ou muito próximos a reservas indígenas, áreas de conservação e aquíferos, como 0 Guarani. Como em diversos outros países, as disputas em torno da liberação ou não do fracking no Brasil têm sido controvertidas e ainda estão em aberto. 
A resistência ao fracking tem sido liderada por ONGs, como a COESUS - Coalizão Não Fracking Brasil e a 350.org, uma organização não governamental norte-americana que atua globalmente no enfrentamento das causas das alterações climáticas. As articulações antifracking vêm mobilizando profissionais, órgãos ambientais públicos, políticos, movimentos sociais, organizações sindicais e empresariais, igrejas para criar restrições legais à exploração do gás de xisto. Além de vir ampliando a visibilidade e a discussão sobre os riscos associados ao fracking, o movimento antifracking coleciona importantes vitórias, como a proibição da exploração no Paraná (Lei n 19.878/ 2019), em Santa Catarina (Lei Estadual no 17.766/2019) e em centenas de municípios. Em outra frente, várias ações do Ministério Público Federal resultaram em liminares suspendendo o efeito da $12^{a}$ rodada de licitações e na exigência de realização prévia da Avaliação Ambiental de Áreas Sedimentares (BRASIL, 2018).

A proibição ao fracking encontra resistência no Maranhão e Piauí (JORNAL GGN, 2019), mas as principais forças pró-fracking estão no governo federal. Além dos editais de licitação, a União procurou retomar o controle dos mecanismos de regulação da atividade. A principal delas foi a aprovação do Decreto Federal n 8.437/2015, que restringe o poder de veto dos estados e municípios, limitando a competência para a concessão do licenciamento ambiental que autoriza a exploração. Apesar de derrotas jurídicas, o governo federal anunciou em 2018 que não desistiria do fracking e que instalaria projetos-piloto de exploração do gás de xisto nos estados do Maranhão, Piauí e Minas Gerais (COALIZÃO NÃO FRACKING BRASIL, 2018). As mudanças político-ideológicas na condução de governos estaduais e federal pós 2019, com a ascensão de teses neoliberais e conservadoras, sugerem novas movimentações e enfrentamentos para o futuro, como 0 acirramento dos conflitos jurisdicionais. Talvez, não seja exagero afirmar que a "guerra" do fracking no Brasil está apenas começando.

\section{CONCLUSÕES}

O debate em torno do faturamento hidráulico, ainda que pouco disseminado no Brasil, aborda um dos temas mais controversos na contemporaneidade. Enquanto tal, ele guarda um enorme potencial científico e político. Inúmeras conexões e implicações, incertezas, relações de poder podem ser depreendidas de experiências em outros países e de seus possíveis desdobramentos ao longo do tempo. $O$ estudo do processo político que anima importantes decisões sobre a adesão ou não ao método e sob que condições é de grande relevância para compreender os embates passados, atuais e futuros e suas repercussões no território e nas políticas públicas, em especial, as ambientais, em múltiplas escalas. 
O advento e a difusão do fraturamento hidráulico para extração do gás de xisto no contexto da neoliberalização da natureza significam uma nova fronteira de acumulação da poderosa indústria dos hidrocarbonetos. Enquanto uma tecnonatureza emergente no contexto de macroprocessos, como o capitaloceno e a acumulação por espoliação, o fracking congrega poderosas forças políticas, econômicas e culturais com grande potencial para desorganizar profunda e negativamente sistemas humanos e não humanos, no limite, gerando zonas sacrificáveis.

Neste artigo, com a exposição de algumas abordagens ao processo político desse fenômeno, procuramos oferecer uma introdução ao que poderá contribuir para o campo de estudo do fracking no País. Evidentemente, muitas outras abordagens e leituras poderiam ser consideradas mais detidamente, a exemplo da Sociedade de Risco (BECK, 2010); da ecologia política (WHITE; WILBERT, 2009; ESCOBAR, 2005) e do neoextrativismo (GUDYNAS, 2015), entre outras. Contudo, esperamos que este artigo tenha sido suficiente para chamar a atenção para o problema e para a complexidade inerente ao fracking e apontar algumas das principais possiblidades de estudá-lo e, ao mesmo tempo, de posicionar-se politicamente por meio das escolhas epistemológicas e teóricas.

Diálogos e contribuições mútuas entre as abordagens apresentadas são salutares, principalmente em um campo de conhecimento em construção. Isso não só é possível, mas necessário, se aceitamos que todas as proposições científicas estão sujeitas a críticas e desenvolvimento fundamentados e que, conforme o relativismo epistemológico - o qual não significa relativismo crítico -, as reivindicações conflitantes sobre um mesmo objeto podem produzir julgamentos racionais entre afirmações concorrentes (JESSOP, 2005). Entretanto, os riscos e incertezas de grandes proporções arrolados pelo fracking e, principalmente, a histórica e estrutural desigualdade na distribuição do poder político, econômico e cultural, e a fragilidade das instituições democráticas em países latino-americanos oportunizam e exigem, tanto analítica quanto politicamente, as abordagens críticas.

O fracking e suas conexões complexas e dinâmicas, com um grande número de atores, decisões políticas e políticas públicas, convocam um olhar interdisciplinar e diálogos de saberes e conhecimentos de diversos campos. Assim, uma ampla agenda de temas está aberta a futuras pesquisas: as mudanças nas relações entre sociedade e natureza; o necessário diálogo entre ciências sociais e ciências naturais; a reconfiguração das seletividades do estado; os novos riscos socioambientais e formas de externalizá-los; a desestabilização do consenso neoliberal com disputas entre capitais setoriais nacionais e internacionais; a intensificação na internacionalização das redes de apoio e resistência ao fracking; as novas alianças e coalizões, muitas imprevisíveis, interescalares; e novos repertórios de discursos e estratégias de apoio e resistência ao fracking. Outros dois temas emergentes e interconectados dessa discussão são a provável captura simbólica do movimento 
antifracking para a legitimação de formas históricas de externalização capitalista de riscos e degradações socioambientais, e os efeitos residuais dessas experiências para o movimento ambiental regional e local.

Para além das conquistas legais e simbólicas, contestadas e provisórias, é preciso conjecturar que o fracking poderá se tornar no Brasil uma alternativa tentadora num futuro próximo, diante da não desprezível reserva brasileira de gás, dos recorrentes apelos às crises energética, econômica e social e da pressão de grandes empresas energéticas multinacionais e dos governos dos seus países de origem. Podemos esperar novas investidas pró-fracking em instâncias do Executivo e do Legislativo federais e em regiões economicamente mais vulneráveis. As forças pró-fracking, até pelo aprendizado e por experiências em outros países, deverão mobilizar práticas e discursos mais eficazes de convencimento do que a estratégia aparentemente desastrada que adotou até o momento.

Contará a favor dessas forças a ascensão de governos federal e estaduais, desde 2019, alinhados ao projeto neoextrativista liberal-conservador norte-americano e que vêm anunciando e operando o desmantelamento das instituições de controle ambiental do País, incluindo os mecanismos de decisões democráticas, de controle social e de produção de informações científicas. Assim, esse cenário renova e aumenta a relevância do engajamento e da articulação da academia com outros movimentos e atores estatais e não estatais. Eles poderão desempenhar um importante papel nas batalhas decisórias sobre a adoção ou não do fracking, e sob que condições, contribuindo para uma melhor compreensão de interesses, estratégias e discursos em jogo, bem como de incertezas, riscos e danos para seres humanos e não humanos.

\section{REFERÊNCIAS}

BARBOSA, V. Brasil tem uma das 10 maiores reservas de gás de xisto. Exame, abr. 2014. Economia. Disponivel em: https://exame.abril.com.br/economia/brasil-tem-uma-das-10-maiores-reservas-de-gasde-xisto/. Acesso em: 3 out. 2018.

BECK, U. Sociedade de Risco: rumo a uma outra modernidade. São Paulo: Editora 34, 2010.

BORINELLI, B. et al. (Des)ordem institucional e ordenamento territorial: considerações sobre a política ambiental de Goiás. Revista de Geografia e Ordenamento do Território(GOT), Lisboa, n. 16, p. 527, 2019.

BORINELLI, B.; HISAMATSU, B.; VITIELLO, S. R. A resistência ao "fracking": notas para a abordagem do processo político no estado do Paraná. In: VIII CONGRESSO IBEROAMERICANO DE ESTUDOS TERRITORIAIS E AMBIENTAIS, 2018, Foz do Iguaçu. Anais .... Foz do Iguaçu: UNIOESTE, 2018. p. 2008-2024. 
BRASIL. 12 ${ }^{\mathrm{a}}$ rodada de licitação de blocos. Disponível em: http://rodadas.anp.gov.br/pt/concessaode-blocos-exploratorios-1/12-rodada-de-licitacao-de-blocos. Acesso em: 10 maio 2018.

CASTREE, Noel. Neoliberalising nature: the logics of deregulation and reregulation. Environment and Planning, v. 40, n. 1, p. 131-152, jan. 2008.

CASTRO, C. J. Sustainable Development: Mainstream and Critical Perspectives. Organization \& Environment, v. 17, n. 2, jun. 2004, p.195-225.

COALIZÃO NÃO FRACKING BRASIL PELO CLIMA, ÁGUA E VIDA. 2018. Fracasso de leilão terrestre é vitória da sociedade. Disponível em: https://naofrackingbrasil.com.br/2018/03/29/fracassode-leilao-terrestre-e-vitoria-da-sociedade/. Acesso em: 20 mar. 2019.

D' ELIA, E.; OCHANDIO, R.¿Qué es la fractura hidráulica o fracking? ¿ Es uma técnica experimental? ¿Cuáles son sus etapas y características? ¿Qué son los hidrocarburos no convencionales? In:

BERTINAT, P. et al. 20 Mitos y realidades del fracking. Buenos Aires: El Colectivo, 2014a. p. 17-27.

DAVIDSON, D. J. Evaluating the effects of living with contamination from the lens of trauma: a case study of fracking development in Alberta, Canada. Environmental Sociology, v. 4, Issue 2, p. 1-14, 2017.

DAVIDSON, D. J.; FRICKEL, S. Understanding Environmental Governance: A Critical Review. Organization \& Environment, v. 17, n. 4, p. 471-492, dec. 2004.

DRYZEK, J. S; DUNLEAVY, P. Theories of the Democratic State. Palgrave Macmillan, 2009

ESCOBAR, A. Depois da Natureza: Passos para uma Ecologia Política Antiessencialista. In: PARREIRA, Clélia; ALIMONDA, Héctor (orgs.). Políticas Públicas Ambientais Latino-Americanas. Brasília: Flacso-Brasil, Editorial Abaré, 2005.

FINEWOOD, M. H.; STROUP, L. J. Fracking and the Neoliberalization of the Hydro-Social Cycle in Pennsylvania's Marcellus Shale. Journal of Contemporary Water Research \& Education, Issue 147, p. 72-79, march 2012.

FINLEY-BROOK, M.; WILLIAMS, T. L.; CARON-SHEPPARD, J. A.; JAROMIN, M. K. Critical energy justice in US natural gas infrastructuring. Energy Research \& Social Science, v. 41, p.176-190, 2018.

GARDINER, L. IE Questions: Is Fracking Dangerous? 2017. Disponível em:

http://insideenergy.org/2017/09/18/ie-questions-is-fracking-dangerous/. Acesso em: 10 set. 2019.

GERTNER, J. George Mitchell. 21 dez. 2013. New York Times Magazine. Disponível em:

https://www.nytimes.com/news/the-lives-they-lived/2013/12/21/george-mitchell/. Acesso em: 7 maio 2019.

GOLDBLATT, D. Teoria social e ambiente. Lisboa: Instituto Piaget, 1996.

GUDYNAS, E. Extractivismos en América del Sur Y sus Efectos Derrame. La Revista, Sociedad Suiza Americanista, Boletín 76, p. 13-23, 2015. Disponivel em: : http://gudynas.com/wp-

content/uploads/GudynasExtractivismosEfectosDerrameSSA2016.pdf. Acesso em: 7 maio 2019. 
HARVEY, D. O Novo Imperialismo. 8 ed. São Paulo: Edições Loyola, 2014

HEIKKILA, T.; BERARDO, R.; WEIBLE, C. M.; YI, H. A Comparative View of Advocacy Coalitions: Exploring Shale Development Politics in the United States, Argentina, and China. Journal of Comparative Policy Analysis: research and practice, v. 21, p. 151-166, mar. 2018.

HOLANDA, J. (org.). Fracking e exploração de recursos não convencionais no Brasil: riscos e ameaças. Rio de Janeiro: Ibase, 2017.

HOWARTH, R. W. A bridge to nowhere: methane emissions and the greenhouse gas footprint of natural gas. Energy Science and Engineering, v. 2, n. 2, p. 47-60, 2014.

HUDGINS, A.; POOLE, A. Framing fracking: private property, common resources, and regimes of governance. Journal of Political Ecology, v. 21, p. 303-319. 2014.

INGOLD, K.; FISCHER, M.; HEIKKILA, T. WEIBLE, C. M. Assessments and Aspirations. In: Policy Debates on Hydraulic Fracturing: Comparing Coalition Politics in North America and Europe. Edited by Christopher M. Weible, Tanya Heikkila, Karin Ingold and Manuel Fischer. Basingstoke, UK: Palgrave Macmillan, 2016. p. 239-264.

JESSOP, B. Critical realism and the strategic-relational approach. New Formations, v. 56, p. 40-53, 2005.

JESSOP, Bob. The Estate: past, present, future. Cambridge: Polity Press, 2016.

JESSOP, Bob; SUM, Ngai-Ling. What is critical? Critical Policy Studies, v. 10, n. 1, p. 105-109, 2016.

JORNAL GGN. Senado debate consequências do fracking para extração de minérios. Disponível em: https://jornalggn.com.br/meio-ambiente/senado-debate-consequencias-do-fracking-para-extracaode-minerios/. Acesso em: 20 ago. 2019.

MCELROY, M; LU, X. Fracking's Future. Natural gas, the economy, and America's energy prospects. Harvard Magazine, p. 24-27, jan / fev. 2013.

MCHENRY, K. A. Fracking Women: A Feminist Critical Analysis of Hydraulic Fracturing in

Pennsylvania. International Journal of Feminist Approaches to Bioethics, v. 10, Issue 2, p. 79-104, 2017.

MERRILL, T. W. Four Questions About Fracking. Case Western Reserve Law Review, v. 63, p. 971 993, 2013.

OBSERVATORIO PETROLERO SUR; D’ELÍA, E. A nivel global, ¿cuál ha sido el rol de las empresas petroleras con respecto a los yacimientos no convencionales? ¿Y el de Estados Unidos? In:

BERTINAT, P. et al. 20 Mitos y realidades del fracking. Buenos Aires: El Colectivo, 2014. p. 147-159.

O'CONNOR, James. ¿Es posible el capitalismo sostenible? Papeles de Población, v. 6, n. 24, abr/jun, 2000. 
OCHANDIO, R.; D’ ELIA, E.¿La fractura hidráulica produce terremotos? ¿ Cuál es la relación entre fracking y sismicidad? In: BERTINAT, P. et al. 20 Mitos y realidades del fracking. Buenos Aires: El Colectivo, 2014. p. 115-120.

OFFE, Claus. Problemas estruturais do Estado capitalista. Rio de Janeiro: Tempo Brasileiro, 1984.

OLOFSSON, K. L. et al. A dominant coalition and policy change: an analysis of shale oil and gas politics in India. Journal of Environmental Policy \& Planning, v. 20, n.5, p. 645-660, 2018.

PARENTI, C. Environment-Making in the Capitalocene Political Ecology of the State. In: MOORE, J. W. Anthropocene or Capitalocene? Nature, History, and the Crisis of Capitalism. Oakland, CA: PM Press, 2016. p. 166-184.

PATEL, R.; MOORE, J. W. A história do mundo em sete coisas baratas: um guia sobre 0 capitalismo, a natureza e o futuro do planeta. Trad. Alberto Gomes. Lisboa: Editorial Presença, 2018.

PETERSON, L. A. et al. Unconventional Oil and Gas Spills: Risks, Mitigation Priorities, and State Reporting Requirements. Environmental Science \& Technology, v. 51, p. 2563-2573, fev. 2017.

POLICY DEBATES ON HYDRAULIC FRACTURING: Comparing Coalition Politics in North America and Europe. Edited by Christopher M. Weible, Tanya Heikkila, Karin Ingold and Manuel Fischer. Basingstoke, UK: Palgrave Macmillan, 2016.

SAQUET M. A; Silva, S. S. Milton Santos: concepções de geografia, espaço e território. Geo UERJ, Rio de Janeiro: ano 10, v. 2, n. 18, p. 24-42, 2008.

SVAMPA, M. ¿Territorios vacíos o Territorios em disputa? ¿ Las sociedade locales, ¿ entre las promesas incumplidas del desarrollo regional y el establecimiento de zonas de sacrifício? ¿ Compite el avance de la explotación de yacimientos no convencionales com economias regionales preexistentes? In: BERTINAT, P. et al. 20 Mitos y realidades del fracking. Buenos Aires: El Colectivo, 2014. p. 147159.

VESALON, L.; CRETAN, R. 'We are not the Wild West': anti-fracking protests in Romania.

Environmental Politics, v. 24, n. 2, p. 288-307, 2015.

VERTEX. Environmental Concerns Related to Hydraulic Fracturing. Disponível em: https://vertexeng.com/blog/environmental-concerns-related-to-hydraulic-fracturing/. Acesso em: 1 set. 2019.

WEIBLE, C. M.; SABATIER, P. A.; McQUEEN, K. Themes and variations: Taking stock of the Advocacy Coalition Framework. The Policy Studies Journal, v. 37, n. 1, p.121-140, 2009.

WHITE, D. F.; WILBERT, C. Inhabiting technonatural time/spaces. In: WHITE, D. F.; WILBERT, C. (Eds.). Technonatures: environments, technologies, spaces, and places in the twenty-first century. Waterloo, Ontario, Canada: Wilfrid Laurier University Press, 2009. p. 1-30.

ZHOURI, A. Produção de conhecimento num 'campo minado'. Introdução. In: Oliveira et al (Org.). Mineração: violências e resistências [livro eletrônico]: um campo aberto à produção de conhecimento no Brasil. Marabá, PA: Editorial iGuana; ABA, 2018. p. 8-26. 